\title{
Model driven architecture engineered land administration in conformance with international standards - illustrated with the Hellenic Cadastre
}

\author{
Styliani Psomadaki ${ }^{1,2^{*}}$, Efi Dimopoulou ${ }^{1}$ and Peter van Oosterom ${ }^{2}$
}

\begin{abstract}
Background: Over the last years, the new role of Land Administration in realising the Information Infrastructure and the need to address spatial and non- spatial land related data exchange between countries emerged and since then, standard models were created and put into use. Two examples of these standards are the Land Administration Domain Model and INSPIRE's Cadastral Parcels. The former is an official international standard with a great deal of prospects; it is based on the 'people - land' relationship and has many applications apart from storing data about properties. The latter is part of a specification framework (set of rules) describing how cadastral parcels can serve as reference for creating a European Spatial Data Infrastructure, enabling cross border dissemination of data.
\end{abstract}

Methods: This paper provides the design of a conceptual model in conformance with both standards. Within this context a Land Administration Domain Model - compliant country profile and the INSPIRE model for Cadastral Parcels are proposed based on characteristic cases from the Hellenic Cadastre. Applying LADM brings along the collective international expertise on various aspects, which are analysed and applied for Greece: including administrative and spatial sources, supporting historical data (versioning), integration of legal (rights) and spatial data (cadastral map), including different register types (Archaeological, Urban, Rural, Forest), and allowing for an integrated 3D registration.

Results: This research results in a model that can be used as a transition from the current cadastral system to a fully LADM- compliant one, taking also into account the INSPIRE directive. The paper further investigates how the developed conceptual model, may be automatically converted to a technical model using Model Driven Architecture. Problematic issues and constraints are highlighted when applying the Model Driven Architecture approach and suggestions for resolving these issues are described.

Conclusions: It is feasible to develop a conceptual model (country profile) which is in conformance with multiple standards, LADM and INSPIRE, because these are well aligned. Cross-boundary land administration is more than ever a very important requirement in todays' global and European community. This is where the adoption of standards comes to play in realising the Information Infrastructure.

Keywords: Land Administration Domain Model (LADM), INSPIRE cadastral parcels, Model Driven Architecture (MDA), Standardisation, Interoperability, Hellenic Cadastre (HC)

\footnotetext{
* Correspondence: S.Psomadaki@student.tudelft.nl

${ }^{1}$ National Technical University of Athens, Athens, Greece

${ }^{2}$ Delft University of Technology, Delft, The Netherlands
} 


\section{Background}

Land Administration Systems (LAS) emerge from the very old times, especially when the management of land becomes more complex [1]. The need for better land administration (LA) and the development of Information and Communication Technologies (ICT) demanded a new approach in the LA domain. Cadastre, as an integral component of LA, was also faced with a new role and vision. The International Federation of Surveyor's (FIG) - Cadastre 2014, proposed six statements on the development of Cadastres, thus initiating a midto long-term vision [2]. Other approaches include the Spatial Data Infrastructures [3, 4], Infrastructure for Spatial Information in the European Community, 3D Cadastres [5], the Land Administration Domain Model [6] and the Social Tenure Domain Model [7, 8]. Behind those approaches, the concepts of standardisation and interoperability are hidden. The former is needed for the optimal operation of LAS, both digital and paper based, while Spatial Data Infrastructures (SDI) cannot be achieved without the latter.

The Hellenic Cadastre $(\mathrm{HC})$ is an ongoing process with the first actual attempts dating back to 1995. The development of the $\mathrm{HC}$ model was not initially based on international standards, practically dealing with issues concerning real property rights in Greece. Furthermore, until 2010, geographic information created by different agencies was characterized by case specific format and limited permission to exchange due to the existing framework and the inadequate cooperation between data producers [9]. This makes the need for a unified cadastral model not limited to specific organisations and software of great importance. In such a situation, standards should be utilized during the whole process.

The Land Administration Domain Model (LADM) became an international standard (ISO 19152), and was formally published on the 1st of December 2012. In 2013 LADM was, announced as a standard by the European Committee for Standardisation (CEN). LADM as a reference model provides a conceptual schema for spatial and non-spatial LA data elements. The LADM aims to provide an extensible basis for the development and refinement of efficient and effective land administration systems, based on Model Driven Architecture (MDA), and to enable involved parties, both within one country and between different countries, to communicate, based on the shared vocabulary implied by the model [10].

Another initiative that deals with standardization and interoperability issues of LA within a cross-border environment is the Infrastructure for Spatial Information in the European Community (INSPIRE), which contributes to the development of the European Spatial Data Infrastructure initially for the purposes of Community environmental policies and policies or activities which may have an impact on the environment. Greece as a member of the European Union is obliged to harmonise its existing datasets to match the requirements of INSPIRE.

This paper provides a conceptual model (country profile) in conformance with multiple standards (Annex A of ISO 19152 and INSPIRE Cadastral Parcels) and a way to automatically convert it to a technical model using MDA is examined.

The paper is organized as follows: Section Background and literature review briefly presents standardisation requirements, with reference to LADM and INSPIRE specifications. It, also, presents the Hellenic Cadastre project and describes its database structure. In Section Research design and methodology a proposed model using both LADM standard and, the LADM compliant, INSPIRE Cadastral Parcels specifications is described. The proposed classes are explained, and so is their convergence with the Hellenic Cadastre ones. MDA is then applied to automatically derive a technical model. The results from the methodological approach are presented within section Results and discussion. Finally, section Conclusions discusses the concluding points in addressing standardisation and interoperability in a more general way concerning current as well as future trends in this domain.

\section{Background and literature review}

Standardisation has always concerned LAS; even for paper based systems standardisation is required, but mostly after the ICT advancements it plays a more important role in digital ones. In the LA domain, standardisation concerns the identification of parcels, documents, persons, surveying data and other issues. It includes the organization of registrations in tables referencing to other components (e.g. source documents and maps), thus facilitating access to archives. It comprises codification and usage of abbreviations (e.g. for administrative areas), while it also concerns workflows [11]. Standardisation makes processes more efficient and reduces the transaction costs of spatial data sharing.

\section{Land administration domain model}

Over the last decades, many standards have emerged: those that deal with the representation of geometry (e.g. OGC's Simple Features), the metadata, the temporal aspect, the modelling of the systems (UML, OCL); however an international standard for cadastral systems had yet to be addressed.

An effort to standardize cadastral systems started in 2002 by Lemmen and van Oosterom, who had the vision of the Core Cadastral Domain Model. Since then, the model has evolved to the international standard Land Administration Domain Model (ISO 19152). The LADM provides an abstract, conceptual model and is organized 
into three packages and one sub-package. The packages in LADM relate to:

- parties (people and organizations)

- basic administrative units, rights, responsibilities and restrictions (ownership rights)

- spatial units (parcels, and the legal space of buildings and utility networks) with the subpackage: spatial sources (surveying), and spatial representations (geometry and topology)

LADM is a simple model with flexible and extensible elements based on the pattern "people - land" relationships (Fig. 1). A full description of ISO 19152 and its development can be found in Lemmen's thesis [6] and the official standard [10].

The value of LADM lies in its extensibility and flexibility meaning that local adoptions and extensions are possible. Country profiles can be used for customising the LADM to meet specific needs [6]. In the official publication of LADM, eight country profiles are included (see [10]). Apart from these, the past years more country profiles have been presented: Malaysia's [12], Poland's [13], Croatia's [14], Cyprus' [15] and that of the Republic of Cape Verde [16]. Some of them have proceeded to the physical database design using MDA [17], while others examine the implementation of a LADM- compliant 3D Cadastre ([12, 18, 19]); all of them however, have the common scope of improving their country's land registers and to achieve interoperability. In addition, the implementation of country profiles based on LADM makes it is possible to compare cadastral management systems (see [20]). Current research aims at the expansion of the administrative part, as well as the expansion based on the Legal Cadastre Domain Model ([20-23]), enabling a more detailed level of modelling interests in land. The current version of LADM limitedly covers legal information within the Annexes F and J.

To support customary and informal tenure in developing countries, the Social Tenure Domain Model (STDM) was also developed based on LADM. With LADM and STDM, information- related components of LA can be registered worldwide in a standardised way [24].

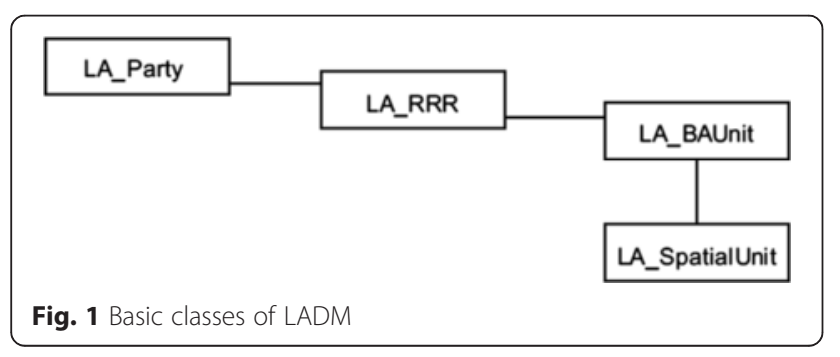

\section{INSPIRE}

Land Administration is a broad topic with many applications which provide a basic infrastructure for implementing land related policies and land management strategies to ensure social equity, economic growth and environmental protection [25]. The European Union acknowledging that LA can contribute to sustainable development and thus environmental policy promoted the Infrastructure for Spatial Information in the European Community Directive (2007/2/EC). The Directive sets the legal framework for the establishment of the Infrastructure for Spatial Information in the European Community [26]. A main task of the INSPIRE programme is to enable interoperability and, when feasible, harmonisation of spatial data sets and services within Europe.

Each Member State has to create and maintain a series of spatial data that are organized into three annexes. To ensure that the spatial data infrastructures of Member States are compatible and usable by the Community in a transboundary context, the Directive requires that common Implementing Rules are adopted in a number of specific areas (Metadata, Data Specifications, Network Services, Data and Service Sharing and Monitoring and Reporting).

\section{Data specifications on cadastral parcels}

Cadastral parcels [27] are included in Annex I of INSPIRE Directive and are thus considered as reference data. The data specifications focus only on the geometrical aspects of cadastral parcels while information about ownership and other rights are outside its scope.

The temporal alignment in the development of LADM and INSPIRE's Cadastral Parcels (CP), led to the development of compatible definitions and common concepts in both models (ISO 2012). The LADM - based model version of CP is included both in the ISO19152 publication (Annex G) and in the Data Specifications of CP (Annex C). However, their differences are immediately noticeable as Cadastral Parcels focus on the geometric aspect, not taking into consideration the rights, restrictions and responsibilities applied to it.

\section{Hellenic cadastre}

The Hellenic Cadastre (HC) is a unified and constantly updated system of information that records the legal, technical and other additional details about real estate properties and the rights on them; this information is kept under the responsibility and guarantee of the State [28]. Registrable rights in the $\mathrm{HC}$ are among others, ownership, usufruct, mortgages, prenotation of mortgages etc. by all beneficiaries, including physical persons and legal entities. Responsibilities are not registered in the HC. However, full ownership may be subject to various 
restrictions, such as mortgages, servitudes, restrictions deriving from horizontal or vertical properties established in a land parcel etc. Planning/ zoning restrictions are only registered by the competent Planning Authorities. The $\mathrm{HC}$ registers "both sides" and therefore, beneficiaries may be positively or negatively affected by rights and restrictions (e.g. ownership/ mortgage or servitude).

The HC's descriptive and spatial information is organised in a property- centred base, thus search can be done either by the property's National Cadastre Code Number (KAEK) which is unique to each property, the address or the beneficiary name.

Today, however, the existing cadastral model is rather unsuitable for data exchange between different agencies. This contradicts the implementation of Directive 2007/ 2/EC with the adoption of Law 3882/2010, which sets the legal framework for the establishment of a National Geospatial Information Infrastructure. In comparison with other European countries, Greece was faced with a big challenge as geospatial information are only developed in an interoperable way since 2010.

The Cadastral Database includes all information (descriptive and spatial) collected during the cadastral survey process. The objects of the cadastral database are organised into logical entities, depending on their feature type.

- The digital descriptive database includes the cadastral information that is collected and technically processed according to the specifications for the development of the HC. The descriptive database of the $\mathrm{HC}$ comprises the following classes (Table 1) and their most important relationships and attributes are depicted in Fig. 2.

- The result of the spatial data processing, which is in accordance with the technical specifications issued by the National Cadastre and Mapping Agency S.A., is included in the cadastral diagrams. It should be mentioned that every piece of land at the municipal level (including roads, streams, special areas etc.) is considered as cadastral parcel and spatial information is fully associated with legal and property information. The explanation behind this tessellation of the space is providing nationwide a full coverage of the land (meaning no gaps and holes). The classes that consist the spatial database of the $\mathrm{HC}$ are depicted in Fig. 3 and described in Table 2.

According to the previous overview, this paper provides a conceptual model (country profile) in conformance with multiple standards (Annex A of ISO 19152 and INSPIRE Cadastral Parcels) and a way to automatically converting it to a technical model using MDA is
Table 1 Classes of the descriptive database

\begin{tabular}{|c|c|}
\hline Class & Description \\
\hline PROP & $\begin{array}{l}\text { Information about real property objects, namely, } \\
\text { cadastral parcels, horizontal and vertical properties, } \\
\text { complex vertical and other elements and registrable } \\
\text { rights, mines, Special Real Property Objects (Anogeia, } \\
\text { Katogeia, Yposkafa, Syrmata, Arcades etc) and other } \\
\text { special properties (roads, rivers etc) }\end{array}$ \\
\hline ADRS & Information about the properties' addresses \\
\hline PROP_ADRS & Information connecting properties to addresses \\
\hline BLD & Information about buildings \\
\hline PROP_BLD & Information connecting buildings to properties \\
\hline VERTREL & Vertical associations of Special Real Property Objects \\
\hline FOREST & Claimed areas from Forest Agency \\
\hline BEN & $\begin{array}{l}\text { Information about all natural and legal entities } \\
\text { (beneficiaries) that have any kind of right on a } \\
\text { property }\end{array}$ \\
\hline RIGHT & Information about recorded rights \\
\hline DOC & $\begin{array}{l}\text { Information about documents collected at Cadastral } \\
\text { Offices }\end{array}$ \\
\hline DOC_BEN_RIGHT & $\begin{array}{l}\text { Information about beneficiaries, documents and } \\
\text { rights }\end{array}$ \\
\hline DOC_ISSUER & $\begin{array}{l}\text { Information of issuing authorities of deeds and all } \\
\text { related documents }\end{array}$ \\
\hline
\end{tabular}

examined. The rest of the paper focuses on the core elements of the LADM; external classes are out of the scope but mentioned for the completeness of the model.

\section{Research design and methodology}

The proposed model comprises a transition from the current cadastral system to a fully LADM - compliant one, taking also into account the INSPIRE directive. The proposed model thus provided (country profile) is in conformance with Annex A of ISO standard and INSPIRE Cadastral Parcels.

\section{LADM}

The transition from the current cadastral system to a fully LADM-compliant one requires some methodological steps to be followed.

As a first step, the convergence of the two models has to be examined. The $\mathrm{HC}$ model is organised into two groups: the descriptive and the spatial one, as with the LADM. Apart from this coarse convergence between the two models, the $\mathrm{HC}$ associates beneficiaries with properties through real property rights, while the spatial part is described by the cadastral parcel, converging again with the LADM approach. Figure 4 depicts the convergence of the core classes of both models. Beneficiaries correspond to LA_Party, Rights to LA_RRR, Properties to LA_BAUnit and Cadastral Parcel to LA_SpatialUnit.

For the design of the LADM country profile for Greece certain requirements were complied: when needed, new 


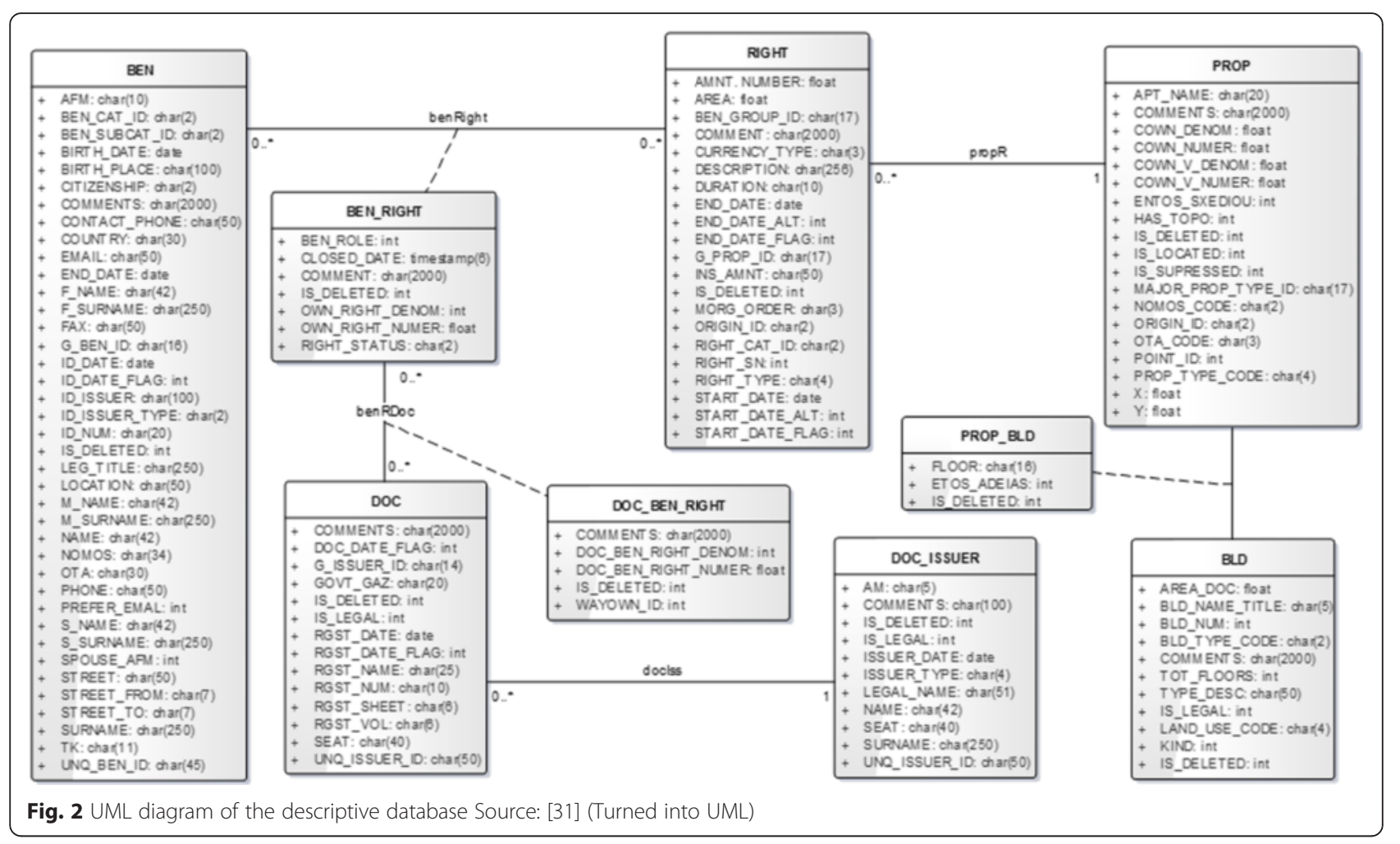

attributes were added so as to maintain the basic characteristics of the HC, while certain LADM classes were not used and code lists were implemented to adjust with national legislation. In order to differentiate the proposed model from other country profiles, the GR_ prefix was used. What is more, to show that the Greek model is conformant with the LADM according to the Abstract test suite (Annex A), it was implemented through providing the inheritance structure between LADM and the tested model, and not as a mapping as this would make the implementation more difficult.

\section{Party Package (Fig. 5)}

GR_Party class includes every kind of person participating in the cadastral survey process. GR_Party corresponds to the classes BEN and DOC_ISSUER of the HC. To explicitly portray the types and roles of the parties in the $\mathrm{HC}$, the attributes role and type are extended according to its defined characteristics. GR_GroupParty and GR_PartyMember are not applied in the Greek case and thus are omitted from the model. In the Party package, two more classes are created for the HC. These are GR_NaturalPerson and GR_LegalEntity that specify GR_Party and comprise all attributes required by the HC model.

\section{Administrative Package (Fig. 5)}

GR_BAUnit class determines all property rights and corresponds to a part of the class PROP of the HC. Apart from the basic attributes defined by LADM, for the unique identification of each cadastral parcel the Hellenic Cadastre Code Number (KAEK) is used. KAEK is a unique 12-digit number, used for accessing and querying the cadastral database. Each of the KAEK 12 digits indicates administrative information concerning the parcel's location, namely the Prefecture where the land parcel is located, the Municipality, Municipal District or Community, the "cadastral sector", the "cadastral section" and finally the serial number of the land parcel within the section. For that reason three new attributes are added to the basic class, namely KAEK, VERT (for the identification of vertical ownerships) and HOR (for the identification of horizontal ownerships).

The abstract class GR_RRR defines the registrable rights, namely rights, restrictions and responsibilities and corresponds to the class RIGHT of the HC. Responsibilities are not registered in the current $\mathrm{HC}$ model, but are used in the conceptual model for the completeness of the proposed model, in case it is required as information in the future.

GR_Mortgage class is a specialization of GR_Restriction and is used to register mortgages in the LADM 


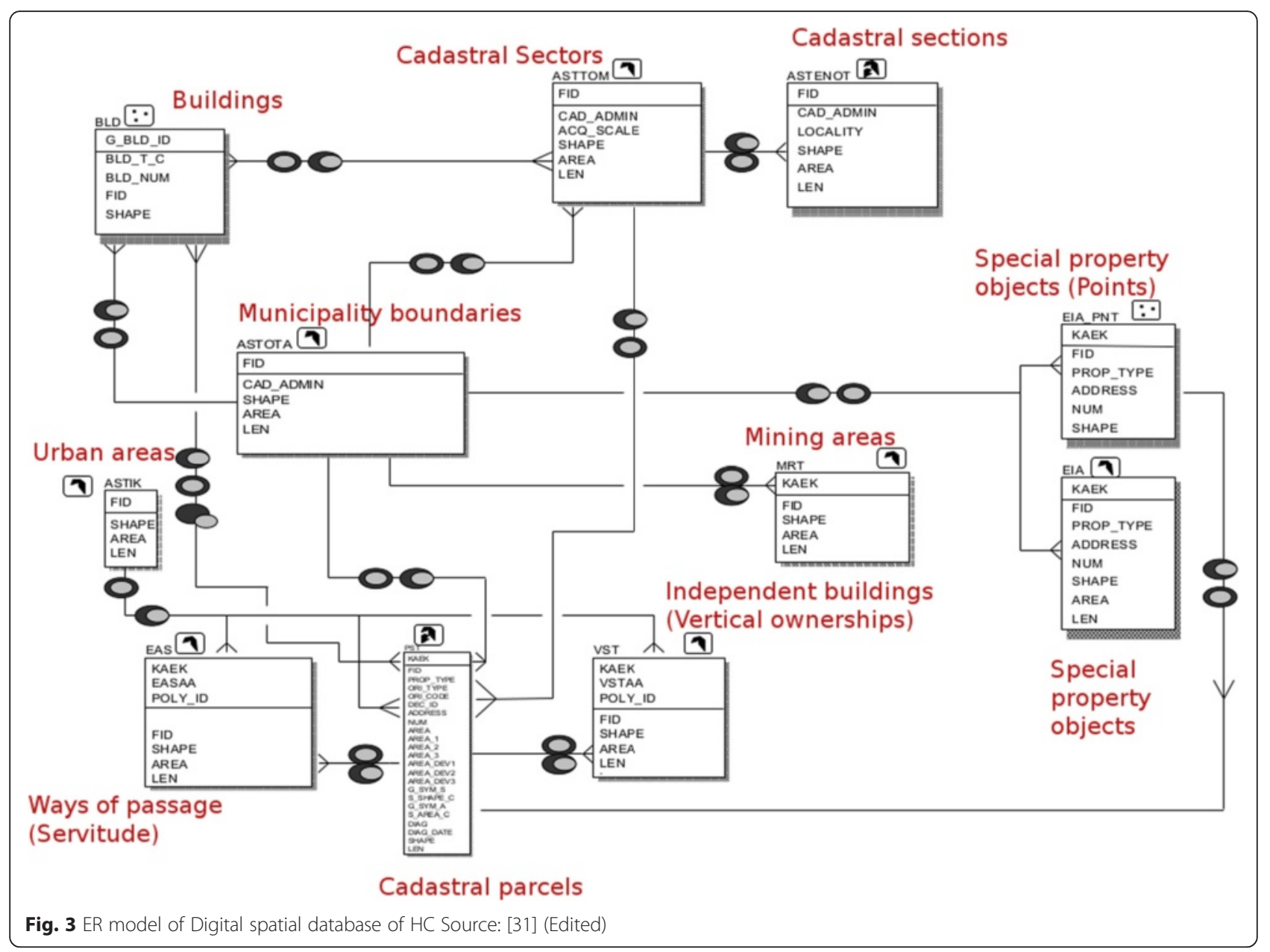

model. The attributes of this class are included in the class RIGHT of the HC.

GR_AdministrativeSource class is the source with the administrative description of the parties involved, rights, restrictions and responsibilities created and the basic administrative units affected. Administrative Source corresponds to classes DOC and DOC_BEN_RIGHT of the $\mathrm{HC}$.

\section{Spatial Unit Package (Fig. 6)}

GR_SpatialUnit class consists of a single area (or multiple areas) of land and/ or water, or a single volume (or multiple volumes) of space and corresponds to part of the PROP class of the HC.

GR_SpatialUnitGroup class consists of spatial units, considered as an entity. In the HC model those entities are Municipalities, Urban and Rural areas, Cadastral Sectors and Cadastral Sections. Municipalities correspond to the class ASTOTA, Urban and Rural areas to the class ASTIK, Sectors to the class ASTTOM and Sections to the class ASTENOT of the digital spatial database.
GR_Building class describes all the elements of buildings and other areas implemented within or out of the cadastral parcel (namely the spatial unit) and corresponds to the class BLD of the HC.

GR_Level class concerns a set of spatial units with a geometric, and/ or topological, and/or thematic coherence. In the $\mathrm{HC}$ scope such a class is not present, however, it could broaden its scope as it could include an Archaeological, Forest, Urban and Rural Cadastre.

Surveying and Representation Sub-package (Fig. 6)

GR_BoundaryFaceString class represents the boundaries of spatial units in two dimensions.

GR_BoundaryFace class represents the boundaries of spatial units in three dimensions.

GR_SpatialSource class includes sources with spatial description of one or more spatial units. This class does not exist explicitly in the current $\mathrm{HC}$ DBMS model, however the information is maintained by the $\mathrm{HC}$ itself.

Indicative codeLists and the External Land Use and Address classes of the model are presented in Figs. 7, 8 and 9. 
Table 2 Classes of spatial database

\begin{tabular}{ll}
\hline Layer & Description \\
\hline PST & Cadastral parcels \\
ASTOTA & Municipality boundaries \\
ASTTOM & Cadastral sectors \\
ASTENOT & Cadastral sections \\
MRT & Mining areas \\
VST & Independent buildings (Vertical ownerships) \\
EAS & Ways of passage (Servitude) \\
BLD & Buildings \\
ASTIK & Urban areas \\
EIA & Special property objects \\
EIA_PNT & Special property objects \\
Roads & Road network \\
OIK & Settlement boundaries \\
CBOUND & Boundaries of urban zone areas \\
DBOUND & Administrative acts (consolidations, land \\
FBOUND & distributions, urban consolidation plans) \\
NOMI & Claimed areas from Forest Agency \\
POI & Land tenure (property possession) \\
POL & Points of interest \\
& Parcel identification marks \\
&
\end{tabular}

\section{Technical model}

The previous methodological steps of transition are followed by the transformation of the logical data model into a physical database. The transformation provides conceptual understanding and reveals the constraints of cadastral data. The first and crucial step of this transformation is to choose the Database Management System (DBMS) so as to reveal requirements and constrains that need to be addressed.

The most commonly used DBMSs are Microsoft Access, MySQL, Oracle Database, PostgreSQL etc. Microsoft Access database may be used for the management of personal data or small businesses, while big companies with many users and extended requirements use a DBMS like the Oracle one. Additionally, when spatial data need to be managed, a Spatial Database Management System needs to be used. Some of the available options are: Oracle Spatial, Microsoft SQL Server, PostGIS (PostgreSQL extension), ESRI's ArcSDE etc.

\section{Model Driven Architecture approach}

As a UML model was implemented for the GR_LADM, the MDA advantages of Enterprise Architect ${ }^{\oplus}$ were taken into consideration. "Model Driven Architecture is a software design approach proposed by the Object Management Group with the objective of improving application development" [29]. For this reason, the Platform PlatformIndependent Model of LADM was transformed into Platform-Specific Model through the production of the Table Diagram (Fig. 10, left). This was then used for the production of the Data Definition Language which was then imported into PostgreSQL. However, as MDA is not yet mature, some limitations where discovered:

- The inheritance from the core LADM, although being considered easier to implement in theory, in the MDA concept is handled in a two table implementation (Parent - Child) where the child element (GR_LADM) is provided with a foreign key to the parent element. In practice this implementation creates difficulties in applying queries in the database while violation of the integrity constraints might take place. What we would rather have is a single table containing both the parent and the child attributes. Another option would be to have the choice how the implementation of the inheritance should take place before performing the Database Table transformation in the EA.

- There is no normative way to translate codeLists into SQL expressions. CodeLists are characterized by their extensibility, in comparison to the

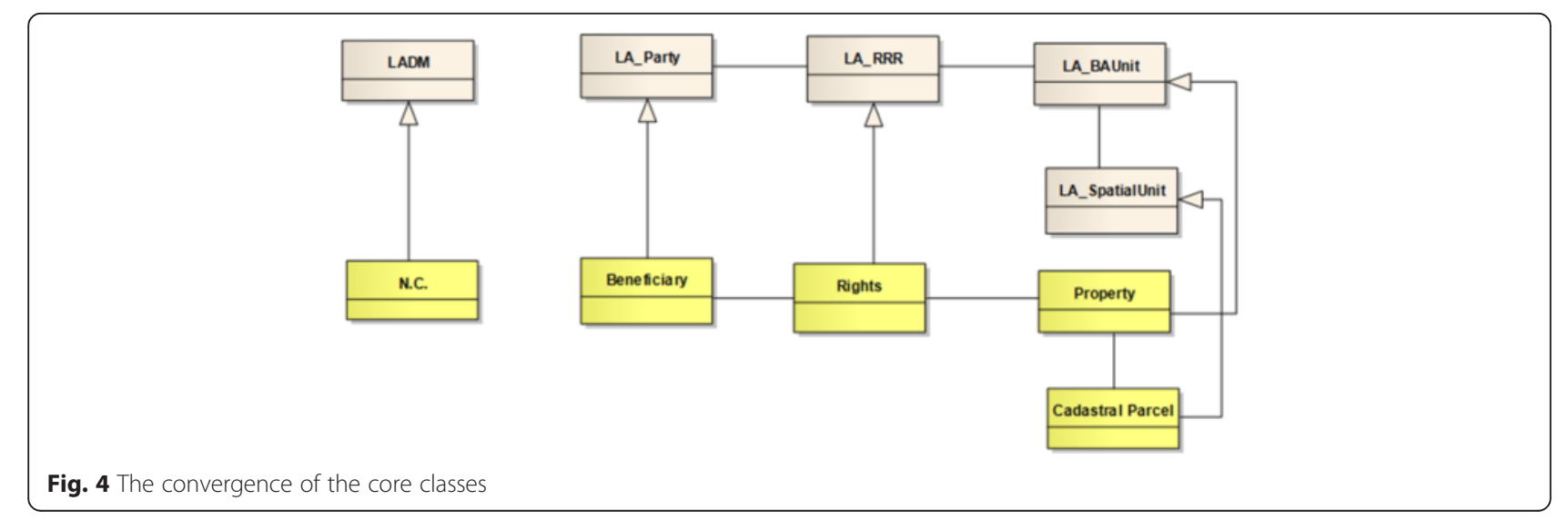




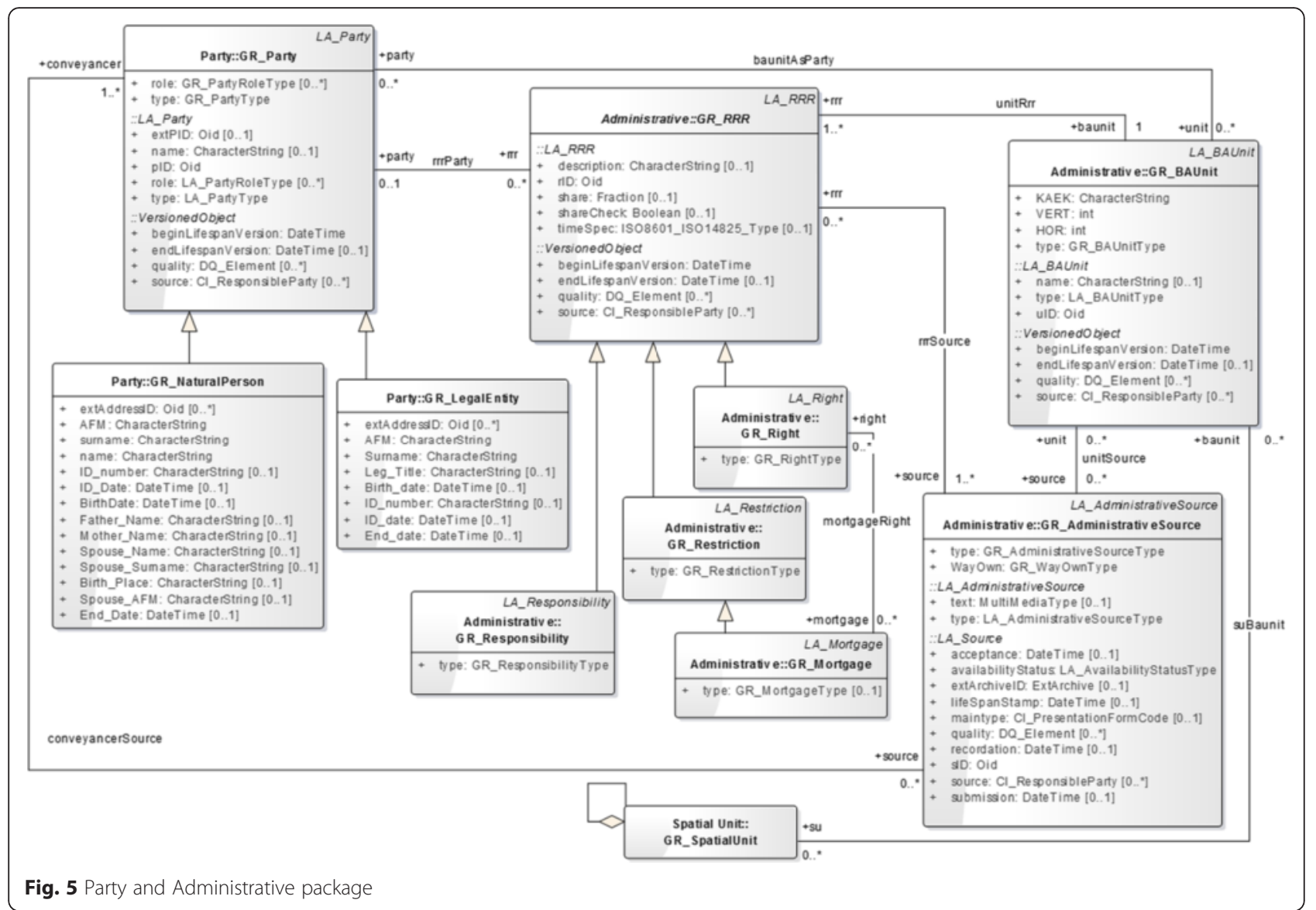

Enumerated Types of PostgreSQL, which are static. What we would rather have is codeLists automatically created as a SQL table with the values present in the UML diagram to be imported into its records. The optimal solution to this deficiency now, is for the SQL expression to be generated by hand.

A part of the generated SQL statement is presented in Annex I (of this paper).

\section{Instance level diagrams}

The previously constructed model is applied in characteristic Greek cases in order to reveal its strengths and constraints concerning its future application. Within this framework instance level cases are constructed in order to provide a better understanding of the model.

Case 1, Usufruct on land parcel: In this case, persons 1 and 3 gain from parental concession the limited ownership on cadastral parcel 0906001 (Fig. 11) while their mother (person 2) keeps the usufruct right for the rest of her life.

Case 2, Horizontal property: In cadastral parcel 2 with KAEK 0906002 (Fig. 12) a horizontal partition has been formed resulting in four distinct properties. The first horizontal property belongs to person 3 who has a partition share of 450/1000 on the land parcel and limited ownership on the first horizontal, while his father (person 4) keeps the usufruct for the rest of his life. The second partition belongs to person 5 who has full ownership on it and co-ownership share of 50/1000 on the land parcel. The third and fourth partition belong to person 6 with coownership share of 450/1000 and 50/1000 and full ownership upon both of the horizontal properties.

\section{INSPIRE cadastral parcels}

The application schema of cadastral parcels consists of four entities. The core -and always available- entity of the cadastral parcels schema is the Cadastral Parcel. The other three entities are Cadastral Zoning (the intermediary areas used to divide the national territory into cadastral parcels), Cadastral Boundary (part of the outline of a cadastral parcel) and Basic Property Unit (the basic unit of properties which may consist of one or more parcels), and are to be provided under certain circumstances. Each entity consists of three kinds of attributes: the obligatory, the voidable and the information about time (also voidable). The voidable characteristics in the INSPIRE context are 'those properties of a spatial object that may not be 


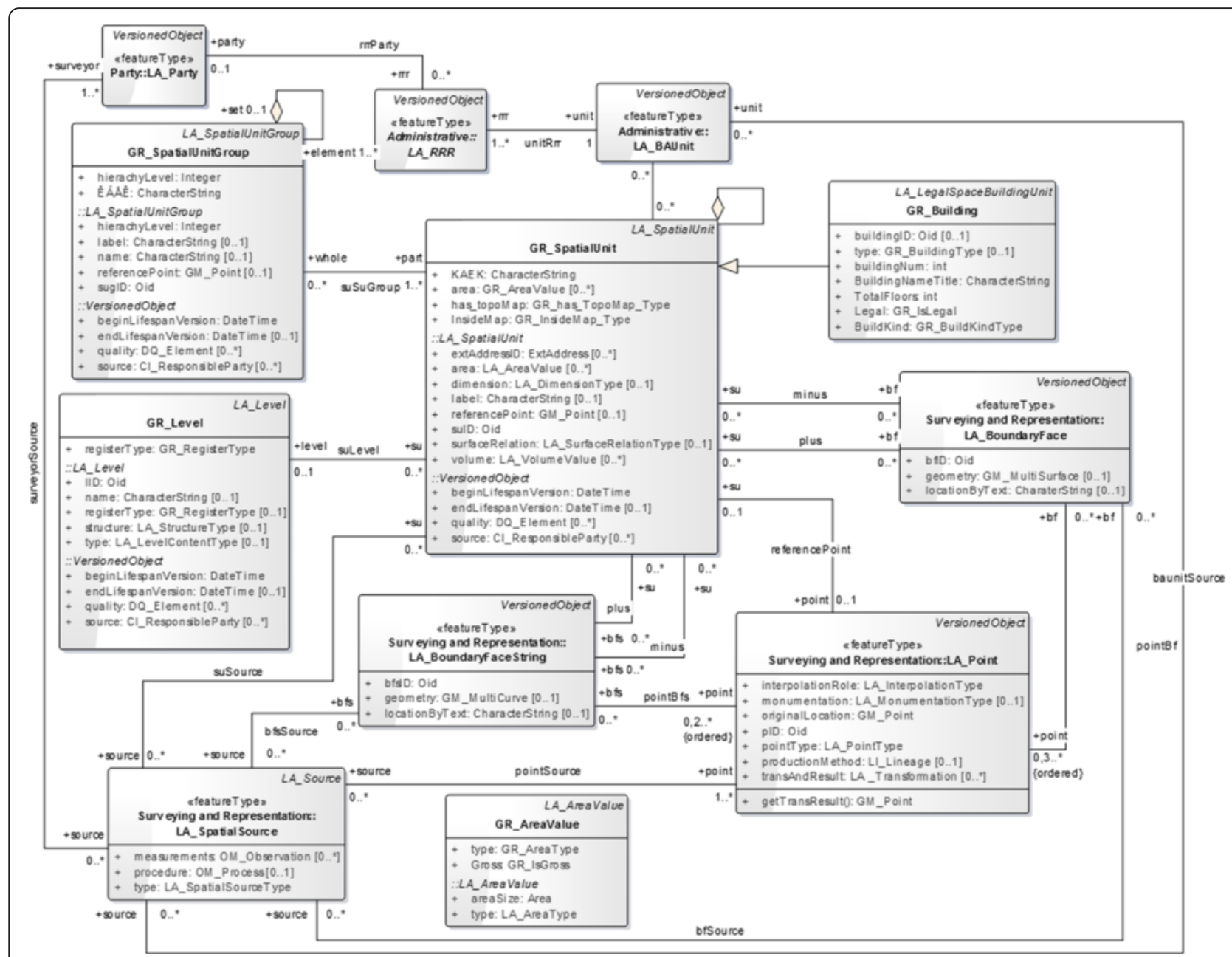

Fig. 6 Spatial Unit package and Surveying and Representation Sub-package

present in some spatial datasets, even though they may be present or applicable in the real world'.

According to the description of technical guidelines concerning Cadastral Parcels only two out of four classes of INSPIRE apply for the $\mathrm{HC}$ case [30]: the Cadastral Parcel and the Cadastral Zoning class. The Cadastral Boundary class will be available from the Member State only if information about the absolute positional accuracy information is recorded for the cadastral boundary. In the $\mathrm{HC}$ model such information is not available and so cadastral boundaries are not provided within the Cadastral Parcels context. Furthermore, Basic Property Units will be used by countries where cadastral references concern basic property units, which is not the case for the $\mathrm{HC}$ where all information is attached to the cadastral parcels. The Cadastral Parcel application schema for the Greek case is presented in Fig. 13, this is a subset of the same HC LADM country profile with the classes GR_SpatialUnit (Cadastral Parcel) and GR_SpatialUnitGroup (Cadastral Zoning). All required INSPIRE attributes are present and a code list for zoning level has been included. INSPIRE Cadastral Parcel model is basically a subset of LADM with specific choices for representing parcel (Annex G of ISO 19152).

However, in this case, other themes of the INSPIRE seem to be very much related with the LADM. For example Addresses is considered an External class in LADM (Greek country profile) and it is expected that there exists a detailed model (data specification) and registration to which can be referred, that is the case of the Greek INSPIRE implementation of addresses. Within an SDI setting, the various registrations can refer to each other. This is also true for buildings and administrative units. For example, in the INSPIRE themes, the municipalities are considered part of the Administrative Units theme and therefore they are not repeated in the Cadastral Zoning. It is expected that the related datasets are harmonised with each other.

The GR_SpatialUnit (Cadastral Parcel) class corresponds to the classes PST, EIA and EIA_PNT of the 


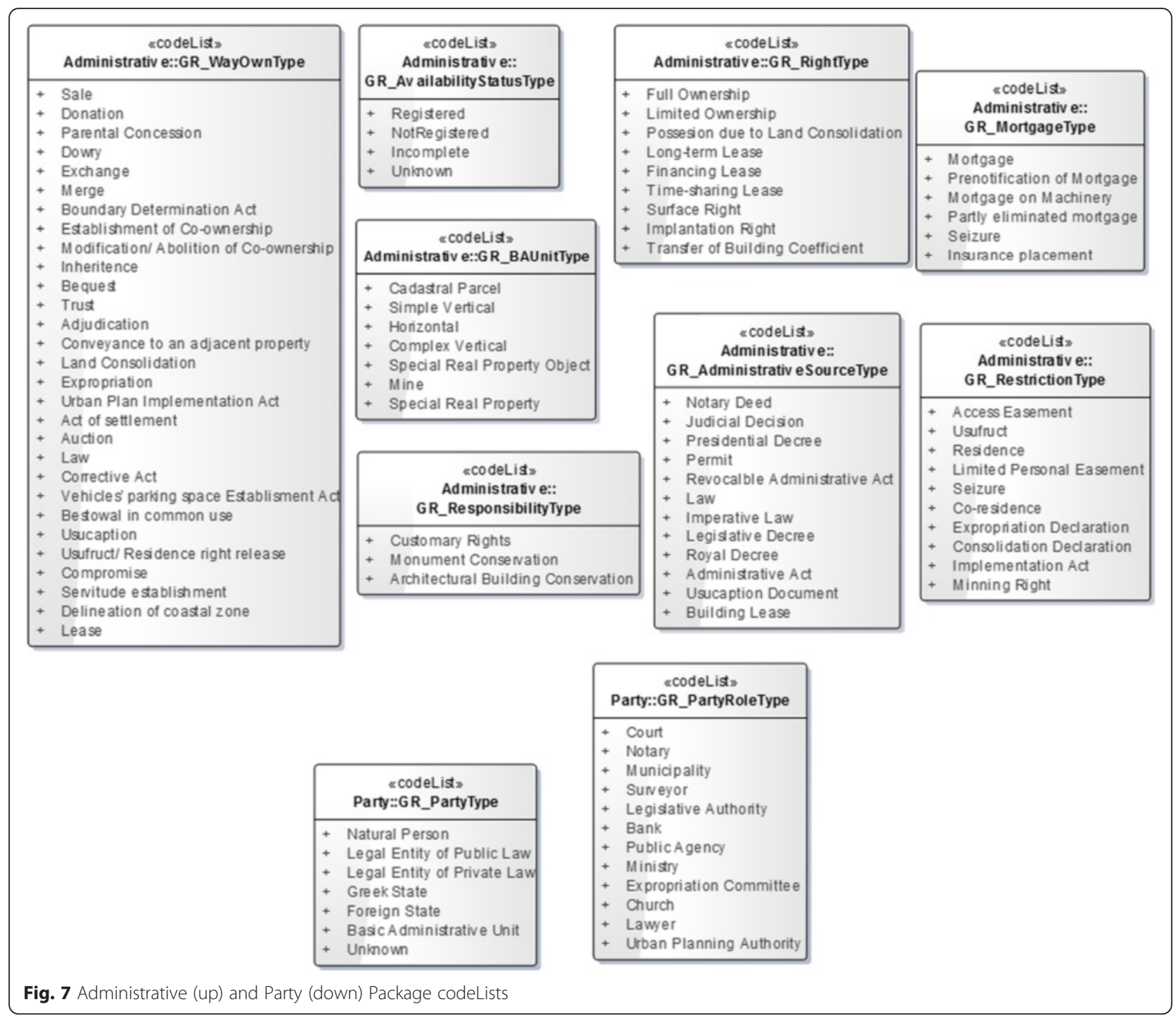

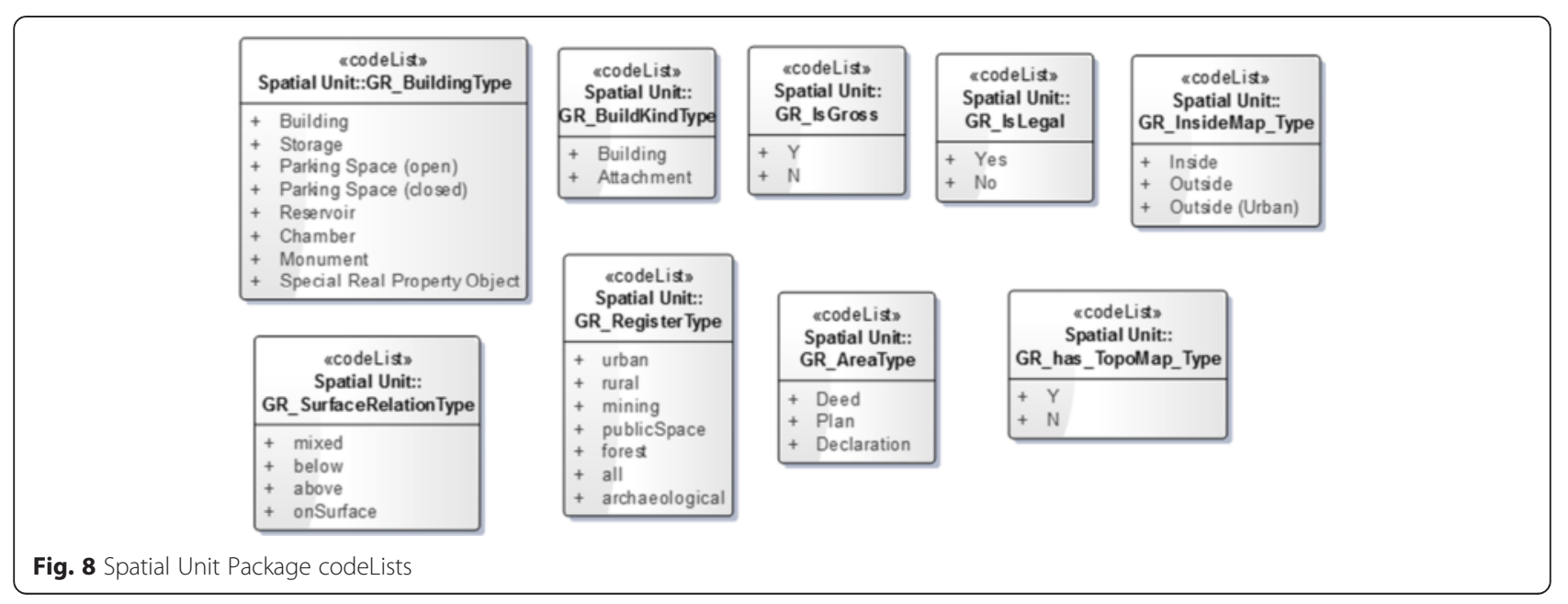




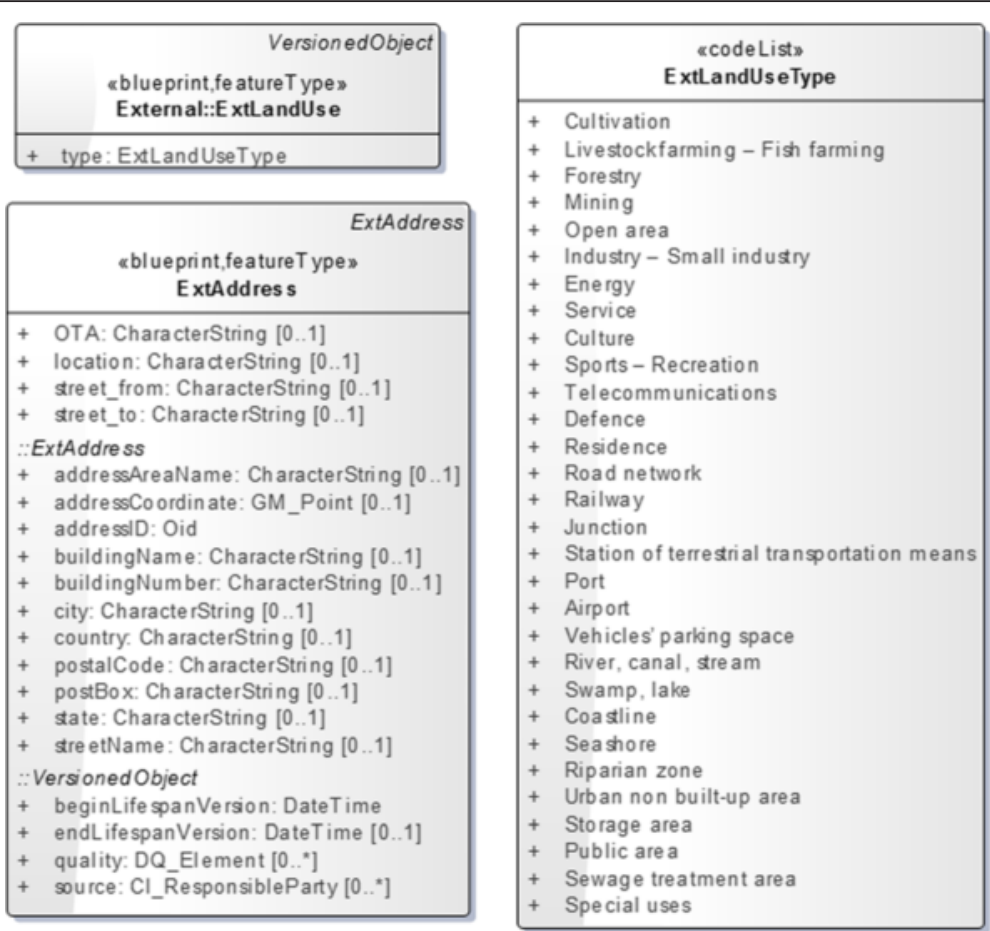

Fig. 9 External classes and land use type

$\mathrm{HC}$ and the GR_SpatialUnitGroup (Cadastral Zoning) correspond to the classes ASTIK, ASTTOM, ASTENOT and MRT. The three levels of the Cadastral Zoning are:

- $1^{\text {st }}$ Order: Urban (or rural) areas as defined by the technical guidelines of the $\mathrm{HC}$.
- $2^{\text {nd }}$ Order: Cadastral Sectors which are formed by Cadastral Sections ( $3^{\text {rd }}$ order).

- $3^{\text {rd }}$ Order: Cadastral Sections which are formed by the Cadastral Parcels.

The availability or unavailability of information by Greece is depicted in Table 3. Column "Obligation"
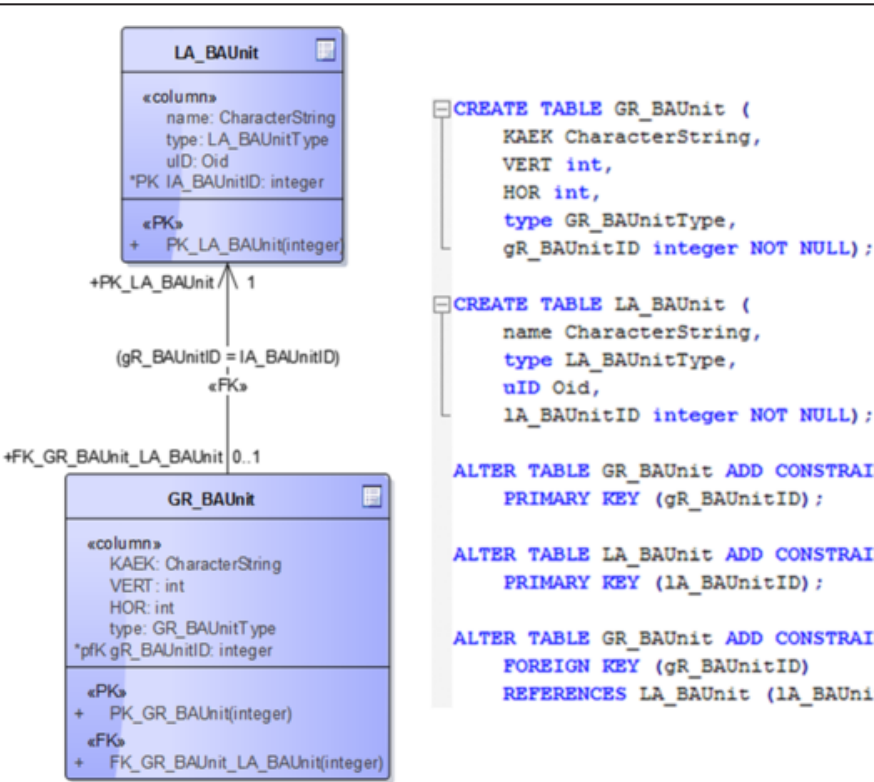

Fig. 10 Inheritance in MDA Left: Table Diagram in EA, Right: Generated SQL statements 


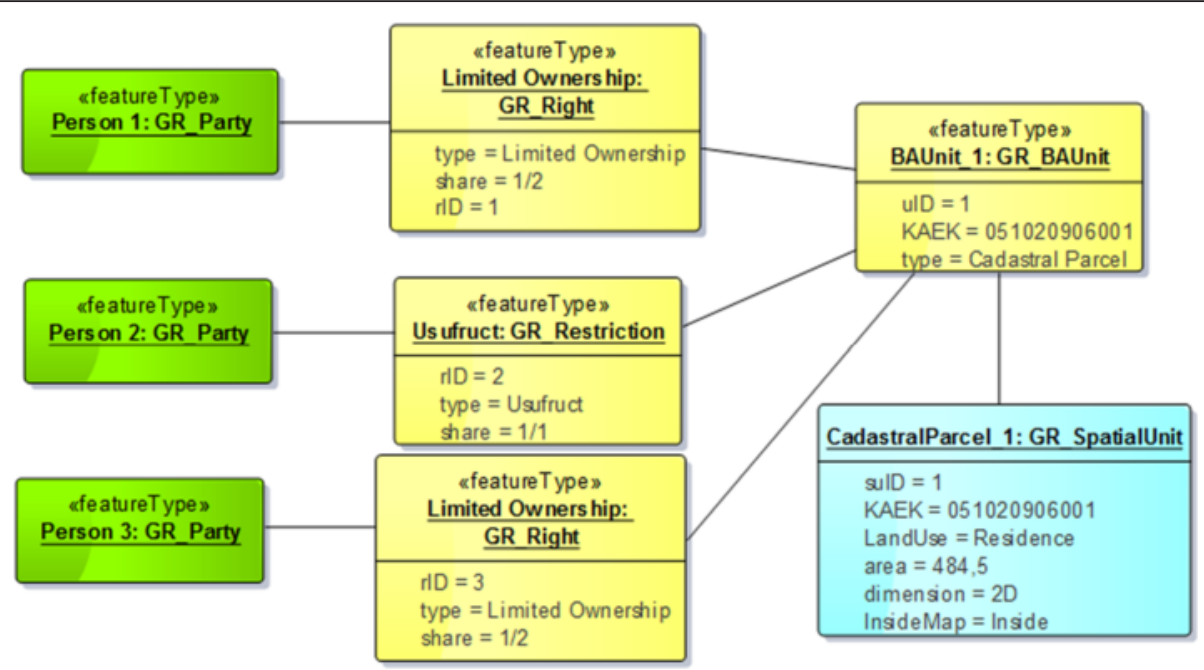

Fig. 11 Usufruct on cadastral parcel

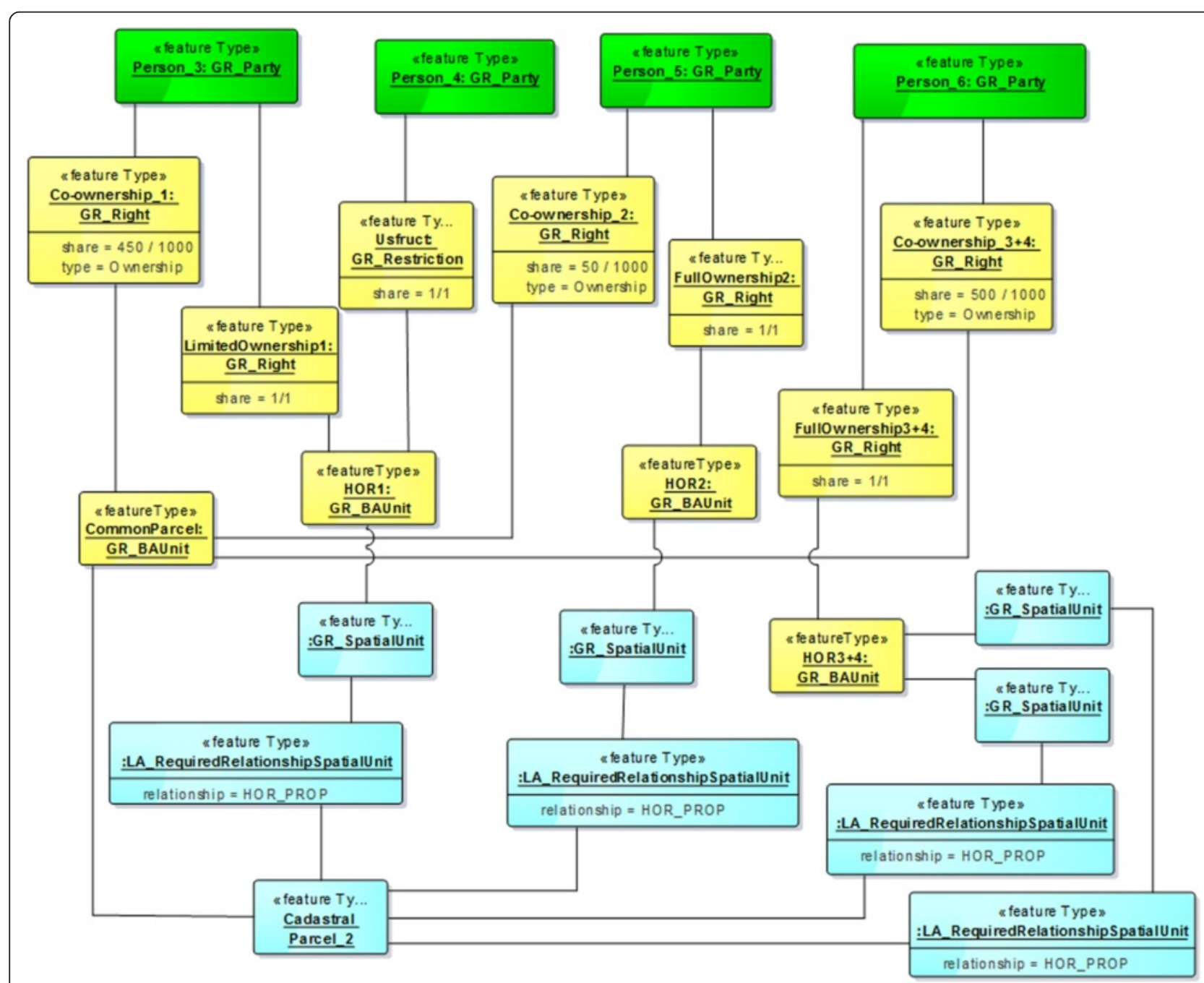

Fig. 12 Horizontal property 


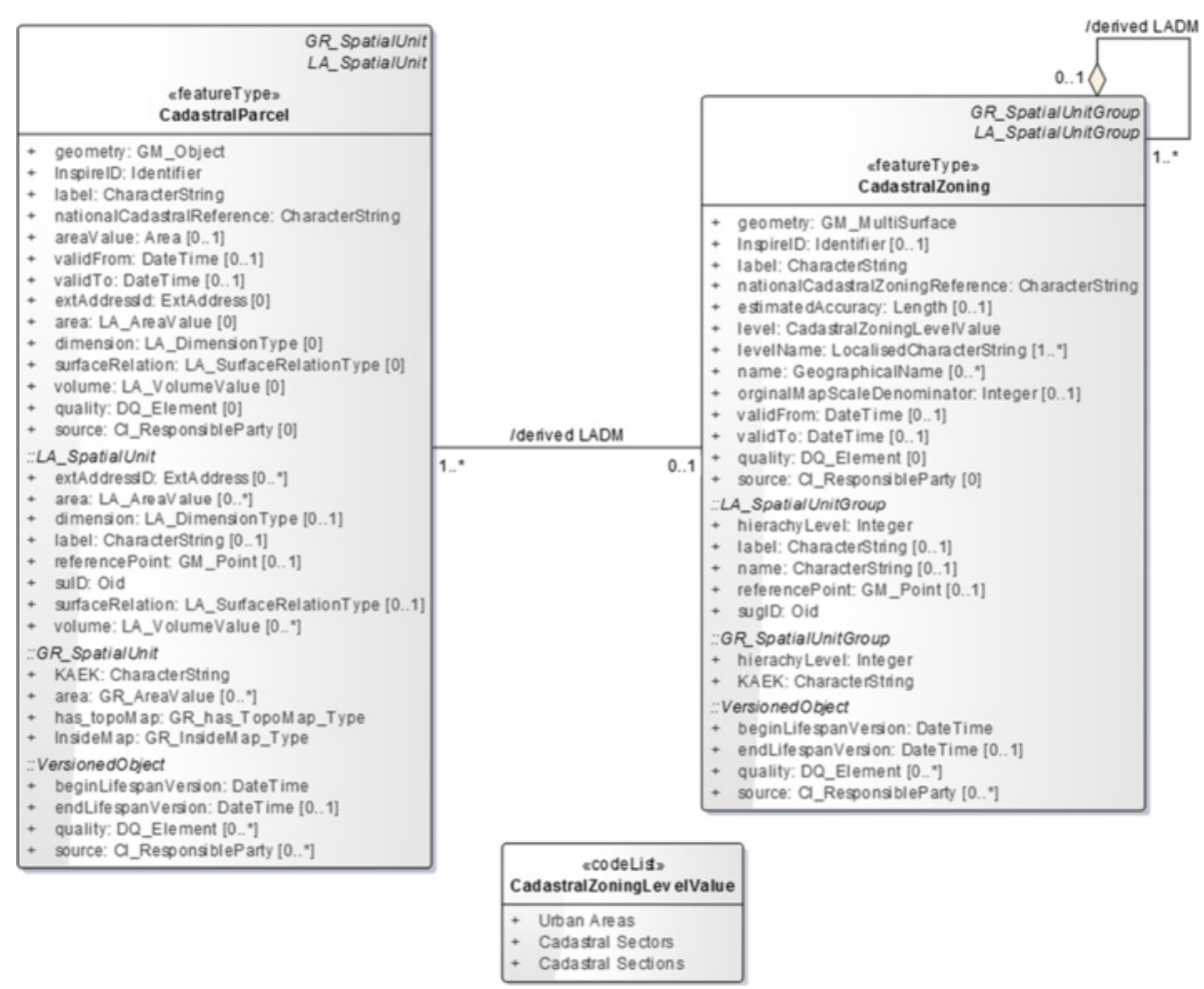

Fig. 13 Cadastral Parcels' Application schema for the Greek case

indicates whether the object is Mandatory or Voidable. Column "Populated" indicates the objects provided by Greece with an X, and "Comment" indicates information about the data.

Similar to the LADM approach, the MDA can be used so as to automatically implement the database schema which can be then put into use by the Member State. The strengths and deficiencies of this approach remain the same as discussed within the LADM approach.

\section{Results and discussion}

The methodological approach as presented in the previous sections for the proposed model results as follows:

The LADM approach revealed the models' extensibility through the use of Hellenic Cadastre cases, thus providing harmonization options with other cadastral systems. Furthermore expanding the $\mathrm{HC}$ with additional information about land use, environmental and social management data, would result in establishing a land information system that fulfils European directives within a common and interoperable framework.

The LADM maintains administrative and spatial sources, as well as historical data, which make the registers and transactions safer. The separate registration of Rights, Restrictions and Responsibilities on the other hand, enables the description of the complete legal situation on land, which can provide the basis for better land administration. It can, also, broaden its scope by the different register types (Archaeological, Urban, Rural, Forest), which have specific characteristics and requirements. Moreover, the LADM approach allows for an integrated 3D registration, without affecting the existing two-dimensional information and the cadastral database.

The methodological procedure brought about a series of constraints, as well. Although LADM enables interoperability, problems of the database maintenance have not been addressed yet, especially when shared between different agencies. What is more, the creation of country profiles with different code lists impedes the interoperability issues between countries, since most of them have different legal frameworks.

As for the physical database design, the MDA approach but for its limitations provides a basis for the implementation of the database. PostgreSQL and PostGIS, both free and open source software, are characterised by their extensibility and compliance with standards and thus prove to be suitable to perform the majority of the cadastral queries in a reliable way. The implementation of LADM using such software increases its flexibility as an international standard and lowers the costs required for the licenses of commercial software.

The INSPIRE approach confirmed the statement of the technical guidelines on Cadastral Parcels, that the 
Table 3 Population of spatial objects, attributes and associations

\begin{tabular}{|c|c|c|c|}
\hline INSPIRE element & Obligation & Populated & Comment \\
\hline \multicolumn{4}{|l|}{ Cadastral Parcel } \\
\hline geometry & M & $x$ & Polygons \\
\hline inspireld & M & $x$ & \\
\hline nationalCadastralReference & M & $x$ & KAEK \\
\hline label & M & $x$ & Part of KAEK \\
\hline referencePoint & V & & \\
\hline areaValue & V & $x$ & \\
\hline validFrom & V & & Available by $\mathrm{HC}$ \\
\hline validTo & V & & Available by $\mathrm{HC}$ \\
\hline beginLifespanVersion & V & $x$ & \\
\hline endLifespanVersion & V & $x$ & \\
\hline Association to cadastral zoning & V & $x$ & \\
\hline Association to basic property unit & V & & \\
\hline Association to administrative unit & V & & \\
\hline \multicolumn{4}{|l|}{ Cadastral Zoning } \\
\hline geometry & M & $x$ & Polygons \\
\hline inspireld & M & $x$ & \\
\hline nationalCadastra|Reference & M & $x$ & KAEK \\
\hline label & M & $x$ & Part of KAEK \\
\hline referencePoint & V & & \\
\hline Level & V & $x$ & From codelist \\
\hline levelName & V & $x$ & From codelist \\
\hline beginLifespanVersion & V & $x$ & \\
\hline endLifespanVersion & V & $x$ & \\
\hline Name & V & & \\
\hline Estimated Accuracy & V & & \\
\hline originalMapScaleDenominator & V & & Spatial data are digital \\
\hline validFrom & V & & Available by $\mathrm{HC}$ \\
\hline validTo & V & & Available by $\mathrm{HC}$ \\
\hline Association to cadastral zoning upper level & V & $x$ & \\
\hline
\end{tabular}

structure of the model is simple and flexible. Moreover it seems that all obligatory data are either present in the current model or can easily be created from the existing ones and be maintained from that moment onwards. This means that INSPIRE can be regarded as a subset of $\mathrm{HC}$ and the transition from the $\mathrm{HC}$ spatial model to an INSPIRE-compliant one can be performed in an automated way. Furthermore, the strict modelling of the Cadastral Parcels, allows for an easy and at all times harmonised creation of metadata that will allow data users to evaluate the adequacy of the data provided and examine whether they are fit for purpose. The cadastral parcel, with its great importance in the decision making process, may significantly support planning and data exchange between different users addressing environmental, social and economic issues in a rational and economic manner.

\section{Conclusions}

For the past decades LAS have managed to address cadastral issues within the boundaries of any country. However, recent advancements and requirements for a cross-boundary land administration require a common approach from the global and European community. For that reason, ISO standards prove to be the best choice when it comes to standardisation and interoperability issues. This is the case with LADM. Furthermore, European Directives and more specifically the INSPIRE Directive, set the legal framework for the creation of a European Spatial Data Infrastructure, where the cadastral information plays a basic role, as with any SDI. So, providing a conceptual model (country profile) which is in conformance with multiple standards (Annex A of ISO 19152 and INSPIRE CP) can extend the role of land 
administration in realizing the Information Infrastructure. What is more, automatically converting the conceptual model to a technical model can bring about advantages when implementing the model, given that certain deficiencies are resolved.

However, in order to gain the best out of the standardisation and interoperability process, the majority of the countries should agree on certain legal aspects. In the case of LADM this would be common codelists for a cross-boundary approach. Other constrains need to be addressed as well, for example the maintenance and updating of data, as this makes a land administration system more reliable and secure.

Finally, it has to be acknowledged that an agreed model based on standards is a first step. The fact that it is based on standards may contribute to its implementation, utilising available software implementations and also overcomes legal implications. Future research could be oriented towards developing a prototype based on the Greek LADM country profile and convert or create actual data. Based on the experience gained with this prototype, the model might need further improvements before running in production. Note that this operational phase includes data collection and maintenance for RRRs and spatial units as core activity.

In conclusion, standardisation and interoperability are gaining more strength in everyday transactions, thus LAS need to adopt them and adapt to them so that people and land can benefit from their advantages.

\section{Annex I - Generated SQL code}

CREATE TABLE baunitAsParty (gR_PartyID integer, gR_BAUnitID integer);

CREATE TABLE GR_BAUnit (KAEK CHAR(12), VERT int, HOR int, type GR_BAUnitType, gR_BAUnitID integer NOT NULL);

CREATE TABLE GR_Party (role GR_PartyRoleType, type GR_PartyType, gR_PartyID integer NOT NULL);

CREATE TABLE GR_RRR (gR_RRRID integer NOT NULL, baunit integer NOT NULL, party integer);

ALTER TABLE GR_BAUnit ADD CONSTRAINT PK_GR_BAUnit PRIMARY KEY (gR_BAUnitID);

ALTER TABLE GR_Party ADD CONSTRAINT PK_GR_Party PRIMARY KEY (gR_PartyID);

ALTER TABLE GR_RRR ADD CONSTRAINT PK_GR_RRR PRIMARY KEY (gR_RRRID);

ALTER TABLE baunitAsParty ADD CONSTRAINT GR_Party FOREIGN KEY (gR_PartyID) REFERENCES GR_Party (gR_PartyID);

ALTER TABLE baunitAsParty ADD CONSTRAINT GR_BAUnit FOREIGN KEY (gR_BAUnitID) REFERENCES GR_BAUnit (gR_BAUnitID);

ALTER TABLE GR_RRR ADD CONSTRAINT unitRrr FOREIGN KEY (baunit) REFERENCES GR_BAUnit (gR_BAUnitID);
ALTER TABLE GR_RRR ADD CONSTRAINT rrrParty FOREIGN KEY (party) REFERENCES GR_Party (gR_PartyID);

\section{Abbreviations}

CEN: European Committee for Standardisation; CP: Cadastral Parcels; FIG: International Federation of Surveyor's; HC: Hellenic Cadastre; ICT: Information and Communication Technologies; INSPIRE: Infrastructure for Spatial Information in the European Community; ISO: International Organization for Standardization; KAEK: National Cadastre Code Number; LA: Land Administration; LADM: Land Administration Domain Model; LAS: Land Administration Systems; MDA: Model Driven Architecture; OCL: Object Constraint Language; SDI: Spatial Data Infrastructure;

STDM: Social Tenure Domain Model; UML: Unified Modelling Language.

\section{Competing interests}

The authors declare that they have no competing interests.

\section{Authors' contributions}

YQM, WJD and CSW conceived of the study, and participated in its design and coordination and helped to draft the manuscript. QJ and LMX participated in the design of the study and drafted the manuscript. YQS and RHM carried out the data collection and statistical analysis. All authors read and approved the final manuscript.

\section{Authors' contributions}

SP carried out the main research based on her Diploma thesis that took place at the School of Rural and Surveying Engineering of National Technical University of Athens. During her Diploma thesis and while drafting the research paper she was supervised by ED, whose guidance was important during all the methodological steps taken and for the completion of the thesis. Finally, $\mathrm{P}$ van $\mathrm{O}$ cooperated with the above mentioned by providing his critical review, improvements and his exprertise on the field making this paper more reliable and original. All authors read and approved the final manuscript.

\section{Acknowledgements}

The authors of this paper would like to express their gratitude to the two anonymous reviewers, whose constructive comments and suggestions, contributed to the formation of the final version of this paper.

Received: 18 April 2015 Accepted: 31 May 2015

Published online: 03 March 2016

References

1. Zevenbergen J. Land administration: to see the change from day to day, Inaugural address. 2009. p. 22.

2. Kaufmann J, Steudler D. Cadastre 2014: A vision for a future cadastral system. Rüdlingen and Bern, Switzerland: International Federation of Surveyors (FIG) Commission7; 1998.

3. Rajabifard A, Williamson IP. Spatial data infrastructures: an initiative to facilitate spatial data sharing. In: Global environmental databases-present situation; future directions. 2002. p. 2.

4. Rajabifard A, Chan TO, Williamson IP. The nature of regional spatial data infrastructures. 1999

5. Stoter JE. 3D cadastre. The Netherlands: Delft University of Technology; 2004.

6. Lemmen $\mathrm{CHJ}$. A domain model for land administration. Delft: TU Delft, Delft University of Technology; 2012.

7. Lemmen C, Augustinus C, van Oosterom P, van der Molen P. The social tenure domain model-specifications of a first draft model. In: Strategic integration of surveying services, FIG Working Week, Hong Kong SAR, China. 2007.

8. Lemmen C. The social tenure domain model: A pro-poor land tool. Copenhagen, Denmark: International Federation of Surveyors, FIG Publication 52; 2010.

9. INSPIRE: Member State report, Greece. 2013.

10. ISO. Geographic information - Land Administration Domain Model (LADM). 2012.

11. Lemmen $\mathrm{CH}$, Van Oosterom PJ. The Land Administration Domain Model Standard. In Proceedings 5th Land Administration Domain Model Workshop, International Federation of Surveyors (FIG), Kuala Lumpur, Malaysia. 2013. p 11-30. 
12. Amalina Zulkifli N, Abdul Rahman A, Van Oosterom PJ. Developing $2 \mathrm{D}$ and 3D cadastral registration system based on LADM: illustrated with Malaysian cases. In: Proceedings 5th Land Administration Domain Model Workshop, International Federation of Surveyors (FIG), Kuala Lumpur, Malaysia. 2013. p 447-64.

13. Bydłosz J. Building LADM Country Cadastral Profile - Case Poland. Kuala Lumpur: 5th Land Administration Domain Model Workshop; 2013.

14. Mađer M, Matijević H, Roić M. Linking Land Registers and Other Official Registers in the Republic of Croatia based on LADM. In: International FIG workshop on the Land Administration Domain Model. 2013.

15. Elia E, Zevenbergen J, Lemmen C, Van Oosterom P. The land administration domain model (LADM) as the reference model for the Cyprus land information system (CLIS). Surv Rev. 2013;45:100-10.

16. Andrade AJB, Carneiro AFT, Santos JC. LADM specification of Relational Database to the Republic of Cape Verde. Kuala Lumpur: 5th Land Administration Domain Model Workshop; 2013.

17. Hespanha J, van Bennekom-Minnema J, Van Oosterom P, Lemmen C. The model driven architecture approach applied to the land administration domain model version 1.1-with focus on constraints specified in the object constraint language. In: fig working week. 2008. p. 19.

18. Budisusanto Y A, T, Muryamto R. LADM Implementation Prototype of 3D Cadastre Information System for Multi-Level Appartment in Indonesia. Kuala Lumpur: 5th Land Administration Domain Model Workshop; 2013.

19. Jeong D, Jang B, Lee J, Hong S, Van Oosterom P, De Zeeuw K, et al. Initial design of an LADM-based 3D Cadastre-Case study from Korea. In: 3rd International FIG Workshop on 3D Cadastres: Developments and practices, Shenzhen, China, 25-26 October 2012. International Federation of Surveyors (FIG)/Urban Planning, Land and Resources Commission of Shenzhen Municipality Shenzhen Urban Planning \& Land Resources Research Center Wuhan University; 2012.

20. Pouliot J, Vasseur M, Boubehrezh A. How the ISO 19152 Land Administration Domain Model performs in the comparison of cadastral systems: A case study of condominium/co-ownership in Quebec (Canada) and Alsace Moselle (France). Comput Environ Urban Syst. 2013;40:68-78.

21. Paasch JM. The Legal cadastral domain model, Joint 'FIG Commission 7' and 'COST Action G9' Workshop on Standardization in the Cadastral Domain. 2004.

22. Paasch JM. Standardization of real property rights and public regulations: The legal cadastral domain model. 2012.

23. Paasch J, Van Oosterom P. Paulsson J, Lemmen C. Specialization of the Land Administration Domain Model (LADM): An Option for Expanding the Legal Profiles. In Proceedings FIG Working Week 2013 in Nigeria-Environment for Sustainability, Abuja, Nigeria, 2013. p 17 .

24. Uitermark H, Van Oosterom P, Zevenbergen J, Lemmen C. From LADM/ STDM to a spatially enabled society: a vision for 2025. In: Land GovernanceMoving towards' land information 2025: next steps-Annual Bank Conference On Land Policy and Administration, 26-27 April 2010. Washington: The World Bank; 2010

25. Williamson IP, Enemark S, Wallace J, Rajabifard A. Land administration for sustainable development. CA: ESRI Press Academic Redlands; 2010.

26. INSPIRE: INfrastructure for SPatial Information in Europe [http://inspire.ec. europa.eu/]

27. INSPIRE Thematic Working Group Cadastral Parcels. D2.8.I.6 INSPIRE Data Specification on Cadastral Parcels - Guidelines, 2009, European Commission Joint Research Centre [http://inspire.ec.europa.eu/documents/Data_ Specifications/INSPIRE_DataSpecification_CP_v3.1.pdf].

28. National Cadastre \& Mapping Agency SA (NCMA SA) [http:/wwww.ktimatologio.gr/]

29. Shekhar S, Xiong H, editors. Encyclopedia of GIS. Publisher Springer, Berlin, 2008;1000. ISBN: 978-0-387-35973-1.

30. Kavadas I. Greek Cadastre Quality Model and Quality Checking of spatial cadastral data. In: QKEN - Plenary meeting; Reykjavik. 2012.

31. Approval of the Technical Specifications and Regulation of estimated fees of the NCMA for Cadastral Studies to create a National Cadastre for the rest of the country. 2013, Law 2362/2013.

\section{Submit your manuscript to a SpringerOpen ${ }^{\circ}$ journal and benefit from:}

- Convenient online submission

- Rigorous peer review

- Immediate publication on acceptance

- Open access: articles freely available online

- High visibility within the field

- Retaining the copyright to your article

Submit your next manuscript at $\gg$ springeropen.com 